\title{
Max Horkheimer: una crítica a la religión
}

\author{
Pável Ernesto Zavala Medina \\ Facultad de Filosofía y Letras \\ Universidad Nacional Autónoma de México \\ pezavala@correo.uaa.mx
}

\section{Proemio}

El presente ensayo tiene por objetivo analizar la crítica que Max Horkheimer hizo a la religión desde la teoría crítica en tres diferentes momentos: durante su etapa de juventud; en la llamada «etapa de crisis», representada por la obra Dialéctica de la Ilustración; y en la etapa final de su pensamiento, que se seguirá a partir de los ensayos y escritos reunidos en Anhelo de Justicia. Es importante destacar que si bien existe una crítica a la religión, también entendida como teología, también se puede encontrar un «rescate» de esta por parte de Horkheimer. Tal «rescate» ha sido, como apunta Juan José Sánchez, mal interpretado tanto por los seguidores de la teoría crítica como por los teólogos:

Los más críticos resaltaron, naturalmente, el fracaso de la Teoría Crítica (TC) en la transformación de la sociedad y la consiguiente búsqueda resignada en la religión de una salida a esta situación aporética por parte de Horkheimer. Los teólogos, por su parte, se 
alegraron en su fuero interno y trataron en el exterior de capitalizar esa postura resignada y, muy especialmente, el «anhelo del totalmente Otro», expresado repetidamente por Horkheimer, como una prueba más que confirma la razón y la verdad de la teología (Sánchez, 1992: 151).

No forma parte del objetivo del presente escrito analizar este debate y tomar postura frente a él, pero se hará referencia a él en varias ocasiones, debido a que de tal debate proviene una de las principales fuentes de información para este ensayo. Es importante mencionar que Horkheimer es dialéctico, es decir, para él una proposición puede ser tanto falsa como verdadera al mismo tiempo o en diferentes momentos, por lo que usará expresiones tales como «el momento de verdad de « $\mathrm{x}^{\prime} » \mathrm{y}$ «el momento de falsedad de « $\mathrm{x}^{\prime} »$. Además de que es un decidido defensor de la finitud tanto del hombre como de sus capacidades, siguiendo las ideas de Kant y de Schopenhauer.

\section{Primera crítica a la religión}

El pensamiento de Horkheimer parte de cuatro elementos importantes: 1) su crítica es movida por la pasión por la verdad, 2) tiene un duelo provocado por el dolor y la esperanza incumplida de las víctimas de la historia, 3) afirma radicalmente la finitud del hombre - es decir, tiene un punto de vista totalmente materialista-, y 4) es solidario con las víctimas de la historia. En este último elemento aparece la idea de que la reflexión no debe quedarse únicamente en el nivel teórico, sino que debe verse reflejada en una praxis. Estos cuatro elementos se mantendrán siempre presentes en su pensamiento. En sus primeros escritos, su punto de partida 
es la hiriente experiencia del mal físico en el mundo (es decir, en la sociedad alemana de los años 20 y 30), tal y como lo muestra uno de sus aforismos de esa época:

Recuerda de qué sufrimientos eres deudor, mientras gozas de sus frutos [...] Ve a la fábrica de tejidos, a las hilanderías, a las plantaciones de algodón: los trabajadores pasan decenios, su vida entera en salas sofocantes y polvorientas o bajo el fuego del sol realizando día a día el mismo trabajo estúpido y desesperante, sin perspectivas de una liberación, sin posibilidades de un desarrollo espiritual [...] Ponte en la situación de estos hombres y piensa por un momento que tú no puedes vivir sin vestido [...] (Horkheimer en Sánchez, 1992: 154).

En este pasaje, Horkheimer, fiel a su postura materialista, parte de una experiencia concreta del sufrimiento, la miseria real, la injusticia y el mal físico, y no de una mera abstracción; a lo que hay que añadir que se muestra consciente de encontrarse en la superestructura, pero deudor de aquellos que se encuentran en la infraestructura. La inconsciencia, el olvido de esta deuda que tienen los intelectuales, así como todos aquellos que sean burgueses, con los obreros y campesinos, va a ser uno de los principales blancos de la crítica de Horkheimer en esta época, ya que dicho olvido ha tenido como consecuencia una ideología que justifica el mal físico, la injusticia y el sufrimiento de las víctimas, que en este período serán sobre todo los proletarios.

Tal ideología se refiere, sobre todo, a la teología y metafísica dominantes en esa época, posterior a la Primera Guerra Mundial, que se caracterizaban por una huída de la sociedad y de sus circunstancias materiales, refugiándose en la esfera de la «pura contemplación» como «pensamiento neu- 
tro». La pretensión de la metafísica de investigar y hablar de la «verdadera esencia» del hombre o de las cosas sin atender a su configuración actual o a sus circunstancias es precisamente resultado de esa huida del mundo, de ese alejamiento de la realidad fáctica, que además permite que el «estado de cosas» presente, la injusticia y el mal físico, no sea alterado. Por su parte la teología hace algo parecido con la religión y la idea de Dios: sus esfuerzos intelectuales van dirigidos no a preservar la trascendencia de Dios, sino a que la imagen divina no refleje nada de la miseria y el sufrimiento de aquellos en quienes se origina el pensamiento sobre Dios, a purificar el pensamiento religioso del barro de esta tierra, del lamento y de las aspiraciones de los hombres. Dios se convierte, finalmente, en un ser totalmente trascendente y de voluntad insondable: «Así se despojó a Dios de toda cualidad cognoscible, y sus caminos se distinguen totalmente de los terrenales. Sus caminos se hicieron tan oscuros como las prácticas mercantiles de los fabricantes y los banqueros» (Horkheimer en Sánchez, 1992: 156). Lo anterior se hace eco de los planteamientos teológicos del Dios absoluto hechos por el nominalismo de la baja Edad Media, y por el Dios oculto del protestantismo calvinista.

Esta especie de «misticismo» hace que la teología, como la metafísica en el caso de la esencia del hombre, pueda hablar de dios sin atentar contra el sistema social existente, lo que no habla muy bien de su pureza, pues al realizar tal alejamiento de Dios o de la esencia del hombre de la realidad fáctica, oculta y legitima la miseria real de las víctimas. Si no es denunciado, este engaño impide tomar conciencia de la miseria y su crudeza e impide que se realice la praxis que la supere. Lo que causa mayor indignación, al parecer de Horkheimer, es que la religión avale y aún promueva el engaño y la mentira, siendo que debería ser la religión la en- 
cargada de dar voz a las víctimas. Es en este punto el que Horkheimer considera parte del momento de verdad de la religión: como expresión y vasija de la esperanza no cumplida de las víctimas de la historia; este momento de verdad sólo puede ser superado por medio de la praxis revolucionaria. El momento de verdad de la religión, con su deseo de justicia y bondad absolutas, depende en gran medida de que acepte su origen material y finito, de lo contrario degenera en teología afirmativa, que oculta esa raíz material y legitima el sufrimiento de los hombres, se convierte en engaño.

\section{Dialéctica de la Ilustración}

En la obra Dialéctica de la Ilustración, escrita en coautoría con Theodor Adorno en 1944, Horkheimer hace varios planteamientos desde los que puede deducirse una crítica a la religión. Es necesario mencionar que tal crítica está subordinada a la crítica que los autores hacen de la cultura occidental, dominada por un proceso de racionalización y abstracción, pero que a su vez recae en el mito, de ahí que se refieran a ese proceso como «dialéctico». Con el término «Ilustración» no se refieren únicamente al movimiento intelectual surgido en Europa durante el siglo XVIII, sino a una tendencia propia del pensamiento occidental, racionalización y abstracción, que comienza desde sus mismos orígenes: con los poemas de Homero y la mitología solar. De acuerdo con estos planteamientos, la civilización occidental ha pasado por diferentes etapas, que van de la magia animista hasta la ciencia y la democracia ilustradas, pasando por la mitología ctónica, la mitología homérica o solar, y la religión monoteísta — tanto en su versión hebrea como cristiana-. Cada una de estas eta- 
pas presenta un mayor grado de abstracción y racionalización, por lo que ven con ojos de desconfianza y aun de odio a la anterior, hasta llegar a la Ilustración, la etapa propiamente racional, pero también en la que la razón se constituye en mito. De acuerdo con Horkheimer y Adorno:

La Ilustración, en el más amplio sentido de pensamiento en continuo progreso, ha perseguido desde siempre el objetivo de liberar a los hombres del miedo y constituirlos en señores. Pero la tierra enteramente ilustrada resplandece bajo el signo de una triunfal calamidad. El programa de la Ilustración era el desencantamiento del mundo. Pretendía disolver los mitos y derrocar la imaginación mediante la ciencia (2006: 59).

Aquí se encuentra encerrado todo el programa de la Ilustración. Desencantamiento del mundo significa la liquidación del animismo, de la proyección de lo subjetivo en la naturaleza, del antropomorfismo, así como un alejamiento del hombre respecto a la naturaleza. Tal desencantamiento comienza no en el siglo XVIII, sino ya en la antigüedad misma, con Homero y sus poemas épicos: en ellos se da un claro paso de la mitología ctónica, en la cual los titanes son idénticos a las fuerzas mismas de la naturaleza, a la mitología olímpica o solar, cuyos dioses representan y dominan las fuerzas de la naturaleza, de las cuales se encuentran ya distanciados. En las leyendas de Homero impera el orden y la unidad, así como la idea de mismidad: «En los estratos homéricos se han depositado los mitos; pero su exposición, la unidad impuesta a las leyendas difusas, es al mismo tiempo la descripción del camino de huida del sujeto de las potencias míticas» (Horkheimer \& Adorno, 2006: 99). En los poemas homéricos se muestra una exaltación de la razón y la astucia, encarnadas en el 
héroe Odiseo, que domina y somete a las fuerzas de la naturaleza, representadas en las criaturas mitológicas como el cíclope, las sirenas y la hechicera Circe, cada uno de estos seres míticos son una amenaza para el sujeto abstracto, pero a la vez son la tentación de volver al estado de la naturaleza, en la cual el sí mismo se pierde, se diluye. El papel de Odiseo es crucial para el futuro desenvolvimiento de Occidente, ya que «el héroe se revela como prototipo del individuo burgués, cuyo concepto se origina en aquella autoafirmación unitaria de la cual el héroe peregrino proporciona el modelo prehistórico» (Horkheimer \& Adorno, 2006: 97).

Odiseo es un héroe peculiar, ya que él no descuella por su fuerza o su habilidad en el combate, como Aquiles, sino por su astucia y racionalidad. La astucia que Odiseo reproduce se encuentra ya en el engaño del sacrificio, ritual que tiene sus orígenes en el estadio de la magia animista:

El momento de engaño en el sacrificio es el modelo de la astucia de Odiseo, así como muchas de sus astucias están depositadas, por así decirlo, en un sacrificio a divinidades naturales [...]. Todas las acciones rituales de los hombres, ejecutadas según un plan, engañan al dios al que son destinadas: lo subordinan al primado de los fines humanos, disuelven su poder; y el engaño cometido contra el dios se transforma sin fracturas en el engaño que los incrédulos sacerdotes cometen contra la comunidad creyente. La astucia tiene su origen en el culto (Horkheimer \& Adorno, 2006: 103).

El engaño a los dioses es el instrumento que usan los sacerdotes para engañar a los creyentes, para someterlos a la ritualidad impuesta por ellos y sojuzgarlos a sus deseos. Esta es una de las críticas a la religión que se pueden encontrar en 
la Dialéctica de la Ilustración: la religión está fundada en el engaño, mismo que se mantendrá presente a lo largo de todo el desenvolvimiento de la civilización occidental, y que hallará su última expresión en el Holocausto llevado a cabo por los nazis. Tal vez el recorrido entre la historia del errabundo Odiseo y las acciones de Hitler parezca muy largo y con un hilo conductor poco claro, no obstante, este fino hilo tiene una gran fuerza: Odiseo, como el nacionalsocialismo, se va a convertir en figura de dominio mediante el engaño del sacrificio. La figura del dominio se perpetúa en Occidente a través de la ideología: la cultura de masas, la religión, el antisemitismo o el fascismo.

El antisemitismo es un esquema rígido, más aún, un ritual de la civilización, y los pogroms son los verdaderos asesinatos rituales. En ellos se demuestra la impotencia de aquello que los podría frenar: de la reflexión, del significado, en último término, de la verdad. En el necio juego del homicidio halla su confirmación la vida dura y hosca a la que hay que adaptarse (Horkheimer \& Adorno, 2006: 216).

El antisemitismo es, pues, una nueva forma de engaño, producto tanto de la religión como de la razón: la religión y el mito han proporcionado el esquema base, la razón le ha dado una justificación y lo ha vuelto más efectivo, proporcionándole las herramientas y los instrumentos adecuados. Lo anterior parece atentar contra los ideales de la Ilustración misma, pero lo cierto es que sus propios principios racionales la conducen a esos resultados: dado que la razón se limita al cálculo y la sistematización, en cuanto al actuar humano se mantiene neutral, siendo incapaz de fijarle fines objetivos, por lo que puede justificar tanto la moral kantiana, que busca 
un bien común acatando la norma, como la del marqués de Sade, que sólo busca el placer propio y egoísta:

Todo pensamiento que no tienda al sistema carece de dirección o es autoritario. La razón no proporciona otra cosa que la idea de unidad sistemática, los elementos formales de una sólida interconexión conceptual. Todo fin objetivo al que puedan referirse los hombres como puesto por la razón es -en el sentido riguroso de la Ilustración- ilusión, mentira, «racionalización», por más que los filósofos se esfuercen particularmente en apartar la atención de esta consecuencia y dirigirla a un sentimiento humanitario (Horkheimer \& Adorno, 2006: 130).

La razón se encuentra, por lo tanto, a igual distancia del «bien» que del «mal», por lo que puede acercarse tanto a uno como al otro de la misma manera. Incluso podría decirse que las categorías de bueno o malo no pueden ser aplicadas a la razón. Pero lo que hace que la razón se decida por uno o por otro es el principio de autoconservación, al que Odiseo se ciñe, así como el individuo burgués, la economía y la ciencia:

La autoconservación es el principio constitutivo de la ciencia, el alma de la tabla de las categorías [...]. Los individuos, obligados a cuidar de sí mismos, desarrollan el yo como la instancia de la previsión y la síntesis panorámica reflexivas; se amplía y se reduce de acuerdo con las perspectivas de independencia económica y propiedad productiva a través de sucesivas generaciones (Horkheimer \& Adorno, 2006: 134).

La autoconservación es lo que mueve tanto a Odiseo como a los sacerdotes o a los fascistas: dado que son débiles y se encuentran en desventaja frente a las fuerzas de la naturale- 
za, hacen uso de la astucia y el engaño para poder sobrevivir, sacrificando a aquellos que caigan en sus ardides, para poder controlar y dominar a las masas. La última forma de dominio que se presentará en Occidente es la industria cultural. Sin embargo, es en la industria cultural, o cultura de masas, donde se revela como el mayor engaño de todos: el sujeto mismo, que había sido el eje sobre el que había girado la civilización occidental, sobre todo a partir de la burguesía capitalista, se vuelve parte de una compleja producción en serie, en la cual pierde su individualidad y su autonomía haciéndolas depender de los dictados de la industria misma: el sí mismo es sacrificado en nombre de su propia conservación. Autoconservación, afirmación de sí mismo, engaño, dominio y sacrificio son constitutivos de la civilización occidental.

\section{Anhelo de justicia: ¿crítica o rescate de la religión?}

Durantes sus últimos años, Horkheimer se expresó, como se mencionó al principio del presente ensayo, de una manera problemática respecto a la religión, ya que se podían interpretar sus escritos o bien como una capitulación de la Teoría Crítica ante la religión y la teología, debido a una supuesta aporía resultado de sus propios principios; o bien como la aceptación de que religión y fe tenían la razón frente a las aspiraciones de la primera Teoría Crítica de transformar la realidad. La aporía habría sido el resultado de la intensa crítica a la razón y el proyecto ilustrado que llevó a cabo en conjunto con Adorno en Dialéctica de la Ilustración, y cuyas conclusiones no parecen ser muy optimistas, ya que no parece haber forma de escapar al proceso dialéctico de la civilización occi- 
dental, y que parece conducir a un autoritarismo inevitable. No obstante, como apunta Juan José Sánchez, ambas lecturas son sesgadas, pues no toman en cuenta el total de las ideas de Horkheimer:

Ambas interpretaciones son demasiado simples para ser verdaderas. Y su coincidencia desde puntos de vista e intereses opuestos da qué pensar. Una lectura de la obra completa de Horkheimer permite reconocer que ambas interpretaciones descansan en un malentendido (1992: 151-52).

En los escritos reunidos bajo el título de Anhelo de Justicia (2000), Horkheimer deja entrever aún una crítica fuerte a la religión, si bien es cierto que le reconoce un momento de verdad, por el cual tiene que ser rescatada. Este rescate se debe a que la religión, en su momento de verdad, puede aportar elementos de resistencia frente a la lógica de la historia, frente al totalitarismo de la sociedad administrada, pero sobre todo, como rescate del individuo y cumplimiento de justicia con las víctimas de la historia: «Horkheimer no reivindica la religión por nostalgia, sino por el mismo impulso de resistencia a esa lógica de la historia que tiende a liquidar toda trascendencia más allá del estado de cosas existente, del poder de los hechos» (Sánchez, 1992: 28). Un aspecto más que va a conservar Horkheimer es la convicción de que el hombre es un ser finito, lo que da mayor coherencia a su pensamiento, ya que él pretende que todo esto sea decantado en una búsqueda de la emancipación, en una praxis revolucionaria que sea capaz de cambiar precisamente las condiciones de las víctimas de la historia.

La crítica a la religión, no obstante, se sigue manteniendo, sobre todo en cuanto que ésta sigue justificando el estado 
de cosas existentes, en vez de dar voz a las víctimas. La crítica se vuelve más cruda y fría ante el hecho de que la religión cristiana ha faltado a sus propios principios. De acuerdo con Horkheimer, la figura de Jesucristo representa las víctimas, las clases más dañadas; lo anterior sería un lugar común, de no ser porque Horkheimer agrega que es por esas víctimas que Jesucristo ataca el orden establecido, intenta revolucionar el estado de cosas existentes, y termina siendo sacrificado él mismo:

Jesús murió por los hombres, no pudo reservarse avaramente para sí y se hizo de todos los que sufren. Los padres de la Iglesia hicieron de ello una religión, es decir, una doctrina, que incluso para el malo era un consuelo. Desde entonces, el cristianismo tuvo tanto éxito en el mundo que el pensamiento de Jesús ya no tuvo nada que ver con la praxis, y menos aún con los que sufren. Quien lee el evangelio y no ve que Jesús murió en contra de sus actuales representantes, ése no sabe leer (Horkheimer, 2000: 227).

La teología se ha encargado de transformar el mensaje de Jesús, adaptándolo a las necesidades del poder en turno. La teología no atiende al anhelo de justicia de las víctimas de la historia, sino que vela únicamente por los intereses de los poderosos, siguiendo el principio de autoconservación y preparándose ella misma para el dominio. De aquí que la teología ya no busque cambiar el estado de cosas existentes, sino que pacta con él, legitimándolo a partir de un principio trascendente e infinito. Como se puede apreciar, la crítica sigue estando presente, no se puede decir que haya habido una reivindicación en este sentido. No obstante, Horkheimer reconoce en la religión dos enseñanzas decisivas: la primera dice que la felicidad se compra con el sufrimiento de otros; y 
la segunda, que el bien absoluto no puede ser representado. La primera está fundamentada en la filosofía de Schopenhauer, y la otra en la prohibición bíblica de hacer imágenes de dios (ver Horkheimer, 2000: 120). Tales enseñanzas no tienen ninguna relación con los dogmas de trascendencia, infinitud o inmortalidad del alma humana, son, antes bien, recordatorios de la finitud del hombre, de su precariedad y mortalidad, y de que no puede desestimar este mundo y esta vida, ya que sólo existe en ellos. Desear alcanzar la infinitud o creer en la inmortalidad del alma y en un más allá, significa negar este mundo, huir de su miseria sin solucionarla, no actuar para mejorarlo.

\section{Conclusiones}

El pensamiento de Horkheimer es bastante complejo y extenso, por lo que no se puede hacer una síntesis de todos sus posibles argumentos que critiquen la religión. Creo, no obstante, que para efectos del presente ensayo, se ha explicado suficientemente las principales líneas que siguió Horkheimer en su crítica a la religión, misma que no perdió fuerza o capituló ante ella en ninguna de sus etapas. Pienso que el rescate que hace Horkheimer de la religión no significa una capitulación o un abandono de la Teoría Crítica, antes bien, es una forma de mantenerse fiel a la praxis propuesta por ella misma, una praxis revolucionaria que busca solucionar el mal físico y el sufrimiento de las víctimas de la historia. El hecho de que el propio Horkheimer vea este punto de coincidencia entre la Teoría Crítica y la religión, muestra además su fidelidad a la crítica misma, que nunca llega adoptar una postura dogmática, sino que queda abierta a nuevas formas de pensar 
y actuar que busquen el mismo fin: el cumplimiento de justicia con aquellos que han sido víctimas del sistema totalitario.

\section{BIBLIOGRAFÍA}

Horkheimer M. \& Adorno Th. W. (2006). Dialéctica de la Ilustración, Juan José Sánchez (trad). Madrid: Trotta.

Horkheimer M. (2000). Anhelo de Justicia: Teoría crítica y religión, Juan José Sánchez ed. Madrid: Trotta.

Sánchez J. J. (1992) «Contra la lógica de la historia. Religión y cuestión de Dios en la obra de M. Horkheimer». En: Gómez Caffarena, J. y Mardones J. M. (Coord.). Cuestiones epistemológicas. Materiales para una filosofía de la religión. I. Barcelona: Anthropos. 


\section{RESUMEN}

El autor analiza la crítica que Max Horkheimer hizo a la religión desde la teoría crítica en tres diferentes momentos: durante su etapa de juventud; en la llamada «etapa de crisis», representada por la obra Dialéctica de la Ilustración; y en la etapa final de su pensamiento, que se seguirá a partir de los ensayos y escritos reunidos en Anhelo de Justicia. Asimismo, destaca que si bien existe una crítica a la religión, también entendida como teología, de igual manera se puede encontrar un «rescate» de ésta por parte de Horkheimer. El autor defiende que este rescate de la religión no significa una capitulación o un abandono de la Teoría Crítica, antes bien, es una forma de mantenerse fiel a la praxis propuesta por ella misma, una praxis revolucionaria que busca solucionar el mal físico y el sufrimiento de las víctimas de la historia.

Palabras clave: Horkheimer, Teoría Crítica, Ilustración y religión.

\section{ABSTRACT}

The author analyzes Max Horkheimer's critic of religion from the critical theory in three different periods: during his youth; in the so-called «crisis stage», represented by the work Dialectic of Enlightenment; and in the final stage of his thought, to be followed from the essays and writings gathered in Longing for Justice. He also notes that while there is a criticism of religion, also understood as theology, we can also find a «rescue» of it by Horkheimer. The author argues that the rescuing of religion does not mean a surrender or abandonment of Critical Theory, rather, is a way to remain faithful to the practice 
proposed by it, a revolutionary praxis that seeks to solve the physical evil and the suffering of the victims of history.

Keywords: Horkheimer, Critical Theory, Enlightenment and religion. 